\title{
The contribution of primary care to health and health systems in low- and middle-income countries: A critical review of major primary care initiatives ${ }^{\text {is }}$
}

\author{
Margaret Elizabeth Kruk ${ }^{\mathrm{a}, *}$, Denis Porignon ${ }^{\mathrm{b}}$, Peter C. Rockers ${ }^{\mathrm{a}}$, Wim Van Lerberghe ${ }^{\mathrm{b}}$ \\ ${ }^{a}$ University of Michigan School of Public Health, Ann Arbor, MI, United States \\ ${ }^{\mathrm{b}}$ Department for Health System Governance and Service Delivery, World Health Organization, Geneva, Switzerland
}

\section{A R T I C L E I N F O}

Article history:

Available online 19 January 2010

\section{Keywords:}

Primary care

Alma Ata

Policy experiments

Program evaluation

Developing countries

Review

Health systems

Access to care

\begin{abstract}
A B S T R A C T
It has been 30 years since the Declaration of Alma Ata. During that time, primary care has been the central strategy for expanding health services in many low- and middle-income countries. The recent global calls to redouble support for primary care highlighted it as a pathway to reaching the health Millennium Development Goals. In this systematic review we described and assessed the contributions of major primary care initiatives implemented in low- and middle-income countries in the past 30 years to a broad range of health system goals. The scope of the programs reviewed was substantial, with several interventions implemented on a national scale. We found that the majority of primary care programs had multiple components from health service delivery to financing reform to building community demand for health care. Although given this integration and the variable quality of the available research it was difficult to attribute effects to the primary care component alone, we found that primary care-focused health initiatives in low- and middle-income countries have improved access to health care, including among the poor, at reasonably low cost. There is also evidence that primary care programs have reduced child mortality and, in some cases, wealth-based disparities in mortality. Lastly, primary care has proven to be an effective platform for health system strengthening in several countries. Future research should focus on understanding how to optimize the delivery of primary care to improve health and achieve other health system objectives (e.g., responsiveness, efficiency) and to what extent models of care can be exported to different settings.
\end{abstract}

(c) 2010 Elsevier Ltd. All rights reserved.

\section{Introduction}

Since the Declaration of Alma Ata in 1978 and, in some instances before, primary health care has been the central, often contentious, strategy for expanding health services in many low- and middleincome countries. The recent 30th anniversary of the Declaration was marked by a global call to redouble support for primary health care.(Chan, 2008; WHO, 2008b).

The World Health Report 2008, draws a distinction between 'primary health care' and 'primary care'. The former is defined broadly as "the mobilization of forces in society-health professionals and lay people, institutions and civil society-around an agenda of transformation of health systems that is driven by the social values of equity, solidarity and participation" while the latter

\footnotetext{
is we are grateful to the editor and three anonymous reviewers for their insightful comments on this paper.

* Corresponding author. Columbia University Mailman School of Public Health, Health Policy and Management, 600 W. 168th Street, New York, NY 10032, United States. Tel.: +1 2123052856 .

E-mail address: mkruk@umich.edu (M.E. Kruk).
}

refers more specifically to aspects of health service provision through the health system. Primary care, the focus of this paper, is a health service delivery approach characterized by first-contact care, ease of access, care for a broad range of health needs, continuity, and the involvement of family and community (see Fig. 1) ("Declaration of Alma-Ata," 1978; Kekki, 2006; Starfield, 1992). The effectiveness of primary care as a health service strategy has typically involved assessing its contribution to meeting health system goals: better health, broad and equitable access to services, responsiveness, and financial protection (WHO, 2000).

There has been substantial research comparing primary care to specialist-focused care in industrialized countries (Atun, 2004; Engstrom, Foldevi, \& Borgquist, 2001; Health Council of the Netherlands, 2004; Macinko, Starfield, \& Shi, 2003; Starfield, Shi, \& Macinko, 2005). For example, in a recent review, Starfield et al. noted that a variety of measures of primary care (e.g., primary care physicians numbers, having a primary care physician as a regular provider, and the availability of community health centers that focus on primary care) had beneficial effects on coverage of preventive and curative services and health outcomes (Franks \& Fiscella, 1998; Starfield et al., 2005; Villalbi et al., 1999). Several 
IOM: Primary care is the provision of integrated, accessible health care services by clinicians who are accountable for addressing a large majority of personal health care needs, developing a sustained partnership with patients, and practicing in the context of family and community.(Donaldson, Yordy, Lohr, \& Venselow, 1996)

Alma Ata: essential health care . . made universally accessible to individuals and families in the community ... through their full participation and at a cost that the community and country can afford.(WHO, 1978)

\section{Starfield: care that is characterized by first contact, accessibility, longitudinality, and comprehensiveness.(Starfield, 1992)}

Fig. 1. Definitions of primary care.

studies have also found that a primary care approach reduces costs compared to specialist care for a range of chronic conditions in the United States (Baicker \& Chandra, 2004; Franks \& Fiscella, 1998; Welch, Miller, Welch, Fisher, \& Wennberg, 1993).

However, the relative effectiveness of primary care versus other health service delivery approaches has not been systematically evaluated in low- and middle-income countries. Although primary care has been on the development agenda for at least the past three decades since Alma Ata, there are few systematic reviews of the impact of primary care on health in the developing world (Macinko, Starfield, \& Erinosho, 2009; Rohde et al., 2008). In addition, while there is an increasing number of single-country evaluations, relatively few of these include non-health goals such as measures of health system responsiveness (Berman, 2000) or economic impacts of seeking (Briggs, Capdegelle, \& Garner, 2001). This gap in the literature may reflect the value that policy makers and researchers assign to these outcomes as well as the difficulties inherent in measuring non-health outcomes.

Evidence on the effects of primary care is especially relevant today as primary care has been highlighted as a potential pathway to reaching the health Millennium Development Goals and as a core strategy for health system strengthening (Chan, 2007, 2008; Montegut, 2007). The recent World Health Report 2008 argued that health system research is necessary to clarify the specific contributions of primary care and to facilitate successful implementation of primary care strategies.(WHO, 2008b) Such research is also important to funders: while external funding for health to the developing world is rising, primary care is competing for the attention of funders and policy makers with a large number of vertical, disease-specific initiatives (Schieber, Gottret, Fleisher, \& Leive, 2007).

Assessing the contribution of primary care in developing countries is challenging. One of the difficulties is the lack of a counterfactual or a control program with which to compare primary care. Whereas specialist-based health services are frequently used for comparison in industrialized countries, these services are not accessible to the majority of populations in low-income countries due to low levels of health spending. In 2004, the average health spending in high-income countries was USD 3810, whereas it was USD 91 in lower-middle-income countries, and USD 24 in low-income countries (Schieber et al., 2007). Even adjusting for purchasing power, the differential between high- and low-income countries is 30 -fold (Schieber et al., 2007). Such spending implies that the vast majority of health services provided are in the realm of primary care. The welldocumented shortages of physicians-particularly specialists-in the poorest countries also means that the most people obtain health care from generalist health workers (nurses, clinical officers, and sometimes GPs) and may never visit a specialist (Chen et al., 2004). Differences in the definitions of primary care also abound, complicating comparison across programs.

An alternative approach is to assess the effects of specific primary care experiments in the developing world on health and health systems. For over thirty years a number of low- and middleincome countries have implemented national and subnational reforms and programs in which a major component is strengthening of primary care provision. These range in design, scope, size, and implementation path but most are aimed at improving health outcomes and equitable access to health services-consistent with the major aims of Alma Ata. Some of these programs have been replicated (completely or in part) across a number of countries and as such may represent important new trends in primary care as well as permitting some limited inference about the generalizability of results.

The aim of this paper was to describe and assess the contribution of large primary care initiatives to a broad range of health system goals in low- and middle-income countries. These include improved health outcomes, service coverage, quality of care, responsiveness to patients and communities as well as equity and efficiency (See Fig. 2) (Kruk \& Freedman, 2008; WHO, 2000). Given the shortcomings of the available evaluation research in this area a formal meta-analysis was not possible. We present here a critical review of a broad range of studies and suggest a research agenda for future work to help strengthen this field.

\section{Methods}

We conducted a critical review of the available literature related to major primary care initiatives in two phases: in the first phase we identified relevant primary care initiatives and in the second phase we searched for publications on the effectiveness of these initiatives. We identified major primary care initiatives implemented in low- and middle-income countries in the past 30 years

\section{Effectiveness}

- intermediate health outcomes

- coverage/utilization rates

- quality of care

- continuity of care

○ adherence to treatment

- ultimate health outcomes: improved health status

- non-health outcomes

- responsiveness (patient satisfaction, accountability, community participation)

Equity

○ health system strengthening

- access to services for vulnerable groups

- equity in health outcomes

- fair financial contribution

- protection from catastrophic health spending

Efficiency

- controlling costs/cost-effectiveness

Fig. 2. Areas of potential contribution of primary care in developing countries. 
by searching Pubmed, Eldis, the WHO and World Bank databases using the terms "primary health care" and "primary care". We also reviewed WHO's World Health Reports for the past ten years and consulted reference lists of key articles. The inclusion criteria for this review were: health programs that were consistent with Starfield's definition of primary care (first contact and accessible care, continuity of care, integrated care for multiple health needs, and coherent links with secondary care), had clear definition of the program and outcomes, presented empirical data on outcomes, and were set in a low- or middle-income country. Where the initiative involved multiple program components, primary care had to comprise a major part. We were particularly interested in programs that were implemented in (either in whole or in part) in more than one country and at large-scale. Setting of care delivery was not a criterion of inclusion as long as it was the point of first contact.

Once the programs were identified, we searched Pubmed, Eldis, and the World Bank and WHO databases for specific evidence on their effectiveness by using program-specific terms, (for example, "integrated primary care", "mid-level providers", "strengthening referral systems") together with "health system", "effectiveness", "equity", "efficiency" and "cost". All abstracts were screened independently by two reviewers. We included peer-reviewed articles, "grey" reports, and policy documents. There were no language restrictions. We categorized the papers identified into conceptual papers that were primarily descriptive and empiric papers that presented data on outputs and outcomes. Among the latter, papers were rated based on the strength of study design. Evidence from studies that employed an experimental design, i.e., randomized comparison groups with baseline and post-intervention data collection, was considered strongest as these designs minimize threats to validity due to potential confounders. Quasi-experimental designs, i.e., nonrandomly selected comparison groups and/or multiple time series, were considered to provide second-best quality of evidence. Finally, evidence from papers with pre-experimental or observational study designs, i.e., single time series, post-hoc only, and other papers without comparison groups, were considered to have weakest validity. In additional to the strength of the design, studies were reviewed to determine the health needs addressed by the initiatives.

\section{Findings}

We identified a total of 16 national programs that addressed one or more pillars of primary care, met the inclusion criteria, and for which reliable data existed. We grouped these into broad categories to highlight similarities and potential trends in primary care experiments across countries (Table 1 ). We found 111 papers discussing the programs, including conceptual papers and qualitative descriptions. From these, we selected 76 papers that met the inclusion criteria for this review. The evidence from these studies for program impact on health and health systems, that is improved health, service coverage, responsiveness, equity, and efficiency, is presented in Table 2. Table 2 also indicates the strength of the evidence presented in the papers. Web Appendix I summarizes the populations reached and health needs addressed by the programs (i.e., child health, maternal health, infectious disease, access to medicines, chronic conditions, or mental health).

First, we note that the scope of the primary care experiments reviewed here is impressive. For example, the integrated primary care programs implemented in Latin America, Thailand, Kerala, and Iran have provided coverage for estimated 240 million people. The Integrated Management of Childhood Illness-a primary care approach to improved case management of childhood disease-has been implemented in districts with a total population of 165 million. These numbers should be interpreted with caution as geographic coverage is not equivalent to utilization but they do
Table 1

Categories of primary care experiments.

1. Large-scale, comprehensive primary care initiatives
1.1. Costa Rica
1.2. Cuba
1.3. Brazil
1.4. Bolivia
1.5. Mexico
1.6. Niger
1.7. Ghana
1.8. Gambia
1.9. Thailand
1.10. Sri Lanka
1.11. Kerala
1.12. Iran
2. Promoting accessible first contact care in fragile states
2.1. Afghanistan
2.2. Liberia
3. Integrating care for multiple health needs at primary level in low-income
countries
3.1. HIV treatment at the primary care level
3.2. Chronic disease treatment at primary care level
3.2. Integrated Management of Childhood Illness (IMCI)
4. Expanding the primary care workforce
4.1. Mid-level primary care providers in Africa
4.2. Family medicine in countries of the former Soviet Union
5. Improving connections with secondary care
5.1. Strengthening referral systems

indicate the broad and growing reach of primary care. As would be expected for a primary care program, most of the experiments tackle several different health needs, in particular child health, infectious diseases and access to essential medicines.

We found that the majority of large primary care programs implemented in low- and middle-income countries over the past 30 years have not focused solely on health service delivery but were complemented by a range of other program interventions, from financing reform to community demand building. For example, many of the major health systems reforms in Latin America and in Southeast Asia have at their core an expansion of primary care. But in all the cases, primary care was one of several aspects of health reform meant to promote access to services. Below, we outline the combined evidence from the studies presented in Table 2 regarding role of primary care in achieving specific goals of the health system.

\section{Effectiveness}

\section{Access to and coverage of health services}

Low- and middle-income countries that have made primary care a cornerstone of their health systems have been successful in expanding coverage to a range of preventive and curative services. Among the countries in this review and irrespective of political system, a clearly defined vision of primary care has often gone handin-hand with a strong commitment to access. This is particularly apparent in the several well-described historic examples (i.e., Cuba, Iran, Sri Lanka and Kerala, India) in which primary care expansion resulted in universal access to health care. In Iran the government's establishment of a primary care facility network led to coverage of $85 \%$ of the rural population within twenty years (Nasseri et al., 1991). Sri Lanka, a relatively poor country that has experienced extensive conflict, covers all of its population with primary care and has utilization levels comparable to industrialized countries (Withanachchi \& Uchida, 2006). More recently, several Latin American countries have invested heavily in primary care expansion with impressive results. Furthermore, several of the reforms in Latin America were implemented with a rigorous evaluation component, 
Table 2

Summary of articles evaluating primary care initiatives in low- and middle-income countries.

\begin{tabular}{|c|c|c|c|c|c|c|c|}
\hline \multirow[t]{2}{*}{ Article reference (see web Appendix I) } & \multirow[t]{2}{*}{ Country } & \multicolumn{3}{|c|}{ Effectiveness } & \multicolumn{2}{|l|}{ Equity } & \multirow[t]{2}{*}{ Efficiency } \\
\hline & & $\begin{array}{l}\text { Coverage/ } \\
\text { quality }\end{array}$ & Health outcomes & $\begin{array}{l}\text { Responsive- } \\
\text { ness }\end{array}$ & $\begin{array}{l}\text { Coverage/ } \\
\text { outcomes }\end{array}$ & Fair financing & \\
\hline (Rosero-Bixby, 2004) & Costa Rica & $\mathrm{X}$ & & & $\mathrm{X}$ & & \\
\hline (Bixby, 2004) & Costa Rica & $\mathrm{XX}$ & $\mathrm{XX}$ & & $\mathrm{XX}$ & & \\
\hline (Iatridis, 1990) & Cuba & & $\mathrm{X}$ & $\mathrm{X}$ & & & $\mathrm{X}$ \\
\hline (Swanson et al., 1995) & Cuba & $\mathrm{X}$ & $\mathrm{X}$ & & & & \\
\hline (Macinko et al., 2007) & Brazil & $\mathrm{XX}$ & $\mathrm{XX}$ & & & & \\
\hline (Macinko et al., 2006) & Brazil & $\mathrm{XX}$ & $\mathrm{XX}$ & & & & \\
\hline (H. Perry et al., 1998) & Bolivia & $\mathrm{XX}$ & $\mathrm{XX}$ & & & & $\mathrm{XX}$ \\
\hline (H. B. Perry et al., 2003) & Bolivia & $\mathrm{XX}$ & $\mathrm{XX}$ & & & & $\mathrm{XX}$ \\
\hline (Arredondo et al., 2006) & Mexico & & & $\mathrm{X}$ & & $\mathrm{X}$ & $\mathrm{X}$ \\
\hline (Arredondo et al., 2008) & Mexico & $\mathrm{X}$ & $\mathrm{X}$ & & $\mathrm{X}$ & $\mathrm{X}$ & \\
\hline (Gakidou et al., 2006) & Mexico & XXX & & XXX & $\mathrm{XXX}$ & & $\mathrm{XXX}$ \\
\hline (Laurell, 2007) & Mexico & $\mathrm{X}$ & & & & & $\mathrm{X}$ \\
\hline (Rivera et al., 2004) & Mexico & & $\mathrm{XXX}$ & & $\mathrm{XXX}$ & & \\
\hline (Magnani et al., 1996) & Niger & $\mathrm{X}$ & $\mathrm{X}$ & & & & \\
\hline (Pence et al., 2007) & Ghana & & $\mathrm{XXX}$ & & & & \\
\hline (Hill et al., 2000) & Gambia & & $\mathrm{XX}$ & & & & \\
\hline (Pannarunothai et al., 2000) & Thailand & $\mathrm{X}$ & & $\mathrm{X}$ & & & $\mathrm{X}$ \\
\hline (Vapattanawong et al., 2007) & Thailand & & & & $\mathrm{XX}$ & & \\
\hline (Wysocki et al., 1990) & Southeast Asia & & $\mathrm{X}$ & & & & \\
\hline (Withanachchi et al., 2006) & Sri Lanka & $\mathrm{X}$ & & & & & $\mathrm{X}$ \\
\hline (Fernando, 2000) & Sri Lanka & & $\mathrm{X}$ & & & & $\mathrm{X}$ \\
\hline (Jayasinghe, 2004) & Sri Lanka & $\mathrm{X}$ & $\mathrm{X}$ & $\mathrm{X}$ & & & $\mathrm{X}$ \\
\hline (Nair, 2004) & Kerala, India & & $\mathrm{X}$ & & $\mathrm{X}$ & & $\mathrm{X}$ \\
\hline (Nag, 1988) & Kerala, India & & $\mathrm{X}$ & & $\mathrm{X}$ & & \\
\hline (Varatharajan et al., 2004) & Kerala, India & & & $\mathrm{X}$ & & & $\mathrm{X}$ \\
\hline (Aghajanian et al., 2007) & Iran & $\mathrm{X}$ & $\mathrm{X}$ & & $\mathrm{X}$ & & \\
\hline (Barzegar et al., 1981) & Iran & $\mathrm{XX}$ & & & & & \\
\hline (Asadi-Lari et al., 2004) & Iran & $\mathrm{XX}$ & $\mathrm{XX}$ & & & & \\
\hline (Currie et al., 2007) & Afghanistan & $\mathrm{X}$ & & & & & \\
\hline (Newbrander, 2007) & Afghanistan & & & & & & $\mathrm{X}$ \\
\hline $\begin{array}{l}\text { (Republic of Liberia Ministry of Health } \\
\text { and Social Welfare, 2007) }\end{array}$ & Liberia & $\mathrm{X}$ & & & & & \\
\hline (Ginsburg et al., 2007) & $\begin{array}{l}\text { Sub-Saharan Africa, India, } \\
\text { Russia, Latin-America }\end{array}$ & $\mathrm{X}$ & & & & & \\
\hline (Mukherjee et al., 2007) & Haiti & $\mathrm{X}$ & & & & & $\mathrm{X}$ \\
\hline (Walton et al., 2004) & Haiti & $\mathrm{XX}$ & & & & & \\
\hline (Peck et al., 2003) & Haiti & $\mathrm{XX}$ & $\mathrm{XX}$ & & & & \\
\hline (Bradley et al., 2008) & Ethiopia & & $\mathrm{X}$ & $\mathrm{X}$ & & & \\
\hline (van der Merwe et al., 2006) & South Africa & $\mathrm{X}$ & $\mathrm{X}$ & & & & \\
\hline (Coetzee et al., 2004) & South Africa & $\mathrm{X}$ & $\mathrm{X}$ & & & & \\
\hline (Harris et al., 2008) & Zambia & $\mathrm{X}$ & $\mathrm{X}$ & & & & \\
\hline (Barth et al., 2008) & South Africa & & $\mathrm{XX}$ & & & & \\
\hline (Boileau et al., 2008) & Burkina Faso, Mali & & $\mathrm{X}$ & & & & \\
\hline (Bolton-Moore et al., 2007) & Zambia & $\mathrm{XX}$ & $\mathrm{XX}$ & & & & \\
\hline (Barnett et al., 2007) & Botswana & $\mathrm{XX}$ & & & & & \\
\hline (Chatterjee et al., 2008) & India & $\mathrm{X}$ & $\mathrm{X}$ & $\mathrm{X}$ & & $\mathrm{X}$ & \\
\hline (Odejide et al., 2002) & Nigeria & $\mathrm{X}$ & & & & & \\
\hline (Mamo et al., 2007) & Ethiopia & $\mathrm{XX}$ & & & & & \\
\hline (Coleman et al., 1998) & South Africa & $\mathrm{X}$ & $\mathrm{X}$ & & & & \\
\hline (Adam et al., 2009) & Brazil & $\mathrm{XX}$ & & & & $\mathrm{XX}$ & \\
\hline (Harkins et al., 2008) & Peru, Honduras & $\mathrm{X}$ & & & & & \\
\hline (Huicho, 2005) & Peru & $\mathrm{X}$ & $\mathrm{X}$ & & & & \\
\hline (Adam et al., 2005) & Tanzania & & & & & $\mathrm{XX}$ & \\
\hline (Simoes et al., 2003) & Uganda, Tanzania, Niger & $\mathrm{x}$ & $\mathrm{X}$ & & & & \\
\hline (Bryce et al., 2005) & Tanzania & $\mathrm{XX}$ & & & & $\mathrm{XX}$ & \\
\hline (Chopra et al., 2005) & South Africa & $\mathrm{X}$ & & & & & \\
\hline (El Arifeen et al., 2004) & Bangladesh & $\mathrm{X}$ & & & & & \\
\hline (Chilopora et al., 2007) & Malawi & $\mathrm{X}$ & $\mathrm{X}$ & & & & \\
\hline (Cumbi et al., 2007) & Mozambique & $\mathrm{X}$ & & $\mathrm{X}$ & $\mathrm{X}$ & & $\mathrm{X}$ \\
\hline (Kruk et al., 2007) & Mozambique & $\mathrm{XX}$ & & & & & $\mathrm{XX}$ \\
\hline (McCoy et al., 2008) & Sub-Saharan Africa & $\mathrm{X}$ & & & & & $\mathrm{X}$ \\
\hline (Santos et al., 2006) & Mozambique & $\mathrm{XX}$ & $\mathrm{XX}$ & & & & \\
\hline (Pereira et al., 2005) & Mozambique & $\mathrm{X}$ & & & $\mathrm{X}$ & & \\
\hline (Vaz et al., 1999) & Mozambique & $\mathrm{X}$ & $\mathrm{X}$ & & & & \\
\hline (Mbaruku et al., 1995) & Tanzania & & $\mathrm{XX}$ & & & & \\
\hline (L. Marcinowicz et al., 2006) & Poland & $\mathrm{X}$ & & $\mathrm{X}$ & & & \\
\hline (Ludmila Marcinowicz et al., 2008) & Poland & $\mathrm{XX}$ & & $\mathrm{XX}$ & & & \\
\hline (Polluste et al., 2007) & Estonia & $\mathrm{X}$ & & $\mathrm{X}$ & & & \\
\hline (Polluste et al., 2004) & Estonia & $\mathrm{X}$ & & $\mathrm{X}$ & & & \\
\hline (Polluste et al., 2000) & Estonia & $\mathrm{X}$ & & $\mathrm{X}$ & & & \\
\hline (Kalda et al., 2004) & Estonia & $\mathrm{x}$ & & $\mathrm{X}$ & & & \\
\hline (Bossyns et al., 2006) & Niger & $\mathrm{XX}$ & & & & & \\
\hline
\end{tabular}


Table 2 (continued)

\begin{tabular}{|c|c|c|c|c|c|c|}
\hline \multirow{2}{*}{\multicolumn{2}{|c|}{ Article reference (see web Appendix I) Country }} & \multicolumn{2}{|c|}{ Effectiveness } & \multicolumn{2}{|l|}{ Equity } & \multirow{2}{*}{ Efficiency } \\
\hline & & $\begin{array}{l}\text { Coverage/ } \\
\text { quality }\end{array}$ & $\begin{array}{c}\text { Health outcomes Responsive- } \\
\text { ness }\end{array}$ & $\begin{array}{l}\text { Coverage/ } \\
\text { outcomes }\end{array}$ & Fair financing & \\
\hline (Majoko et al., 2005) & Zimbabwe & $\mathrm{X}$ & \multicolumn{4}{|l|}{$X$} \\
\hline (Bossyns et al., 2005) & Niger & $\mathrm{X}$ & \multicolumn{2}{|l|}{$\mathrm{X}$} & $\mathrm{X}$ & \multirow[t]{5}{*}{$\mathrm{X}$} \\
\hline (Mugisho et al., 2003) & Democratic Republic of Congo & $\mathrm{XX}$ & \multicolumn{3}{|l|}{$\mathrm{XX}$} & \\
\hline (Maine et al., 1996) & Bangladesh & $\mathrm{x}$ & \multicolumn{3}{|l|}{$\mathrm{X}$} & \\
\hline (Fauveau et al., 1991) & Bangladesh & & \multicolumn{3}{|l|}{$\mathrm{XXX}$} & \\
\hline (Porignon et al., 1998) & Democratic Republic of Congo & $\mathrm{X}$ & \multicolumn{3}{|l|}{$\mathrm{X}$} & \\
\hline
\end{tabular}

Note: References for Table 2 can be found in Web Appendix 2.

$\mathrm{XXX}=$ experimental study (involving randomly selected comparison group)

$\mathrm{XX}=$ quasi-experimental study (involving non-randomly selected comparison group or multiple time-series observations)

$\mathrm{X}=$ pre-experimental study (observational data, no comparison group)

providing strong evidence of their effectiveness (Table 2). Between 1994 and 2008, Brazil expanded a broad set of primary care services to over half of its population, or 86 million people (Ministry of Health of Brazil Department of Primary Care, 2007). Mexico saw an increase in utilization of 11 key preventive and curative interventions for people participating in Seguro Popular-an insurance program covering primary care consultations and medicines (Gakidou et al., 2006). Costa Rica's expansion of primary care teams resulted in substantial falls in unmet need for health care compared to areas without the teams (Rosero-Bixby, 2004). Post-conflict countries such as Afghanistan, Rwanda, Democratic Republic of Congo and Liberia are implementing basic packages of health services (BPHS) - an integrated set of essential services generally provided at primary care facilities - as the vehicle for rapidly scaling access, with encouraging early results in utilization of maternal and child health services in Afghanistan and Rwanda, despite ongoing insecurity (Johns Hopkins University \& Indian Institute of Health Management Research, 2006). Smaller primary care-focused initiatives such as the Integrated Management of Childhood Illness, have improved access to child health services along with service quality in several low-income countries (Tanzania IMCI Multicountry Evaluation Health Facility Survey Study Group, 2004). Innovations in the primary health workforce, in particular the training and large-scale deployment of non-physician clinicians in Africa have improved access to primary care throughout rural Africa (Mullan \& Frehywot, 2007). The integration of improved child health and chronic disease services as well as HIV diagnosis and treatment with primary care at the community level has been demonstrated to be successful in even the most resource-constrained countries and has resulted in improving geographic availability of life-saving services to rural populations. While the impacts demonstrated by these small-scale initiatives are promising, we note that few have been subjected to rigorous evaluation methods (Table 2). Work is ongoing to determine additional health services that may best be provided as part of a primary care system, including oral health care (van Palenstein Helderman et al., 1999) and mental health care (WHO, 2008a). Indeed, mental health care was included in the primary care strategy of Iran as early as the 1980's (WHO, 2008a).

\section{Improved health}

Improvement in health status and, in particular, reductions in premature and avoidable mortality have been documented in the large, national-level primary care reforms in Latin America and Asia. Indeed, more than half of the studies reviewed here measured health outcomes directly (Table 2). As expected, most of the health improvements have been in primary care-sensitive mortality-particularly child mortality and mortality from infectious disease. Under-five mortality and life-expectancy in Cuba, Sri Lanka, and Iran rival those of wealthier countries. Several decades of primary care expansion in Costa Rica has been credited for child mortality better than wealthier neighbors (Unger, De Paepe, Buitron, \& Soors, 2008). In Brazil infant mortality fell $13 \%$ coincident with an increase in the coverage with primary care teams from 14\% to 60\% (Macinko, Guanais, de Fatima, \& de Souza, 2006). Thailand reduced its underfive mortality rate by $32 \%$, in part due to an aggressive expansion of rural primary care (Vapattanawong et al., 2007). In Afghanistan, where the government and its development partners have been contracting with NGOs to deliver a standardized package of primary care services, under-five mortality has declined from 257 in 2001 to 191 in 2006 (Ministry of Public Health of Afghanistan, 2008). Several additional countries reported positive impacts, generally on underfive mortality, from a range of primary care programs (Brockerhoff \& Derose, 1996; Dugbatey, 1999; Hill, MacLeod, Joof, Gomez, \& Walraven, 2000; Magnani et al., 1996; Pence, Nyarko, Phillips, \& Debpuur, 2007; Perry, Shanklin, \& Schroeder, 2003; Perry et al., 1998; Velema, Alihonou, Gandaho, \& Hounye, 1991). While it is not possible to unequivocally attribute mortality reductions to primary care alone in these countries, as all of the initiatives involved multiple components, it is likely that the concerted effort to strengthen primary care services was a core contributor to the observed declines. The findings of positive impact on health are consistent with a recent review of primary care by Macinko et al. (Macinko et al., 2009).

\section{Responsiveness}

There is less data on the responsiveness dimension of primary care performance. Indeed, only two studies reviewed here applied a quasi-experimental or experimental study design to evaluate the effect of primary care reforms on responsiveness (Table 2). One of the arguments made in the rural-focused reforms is that local delivery of health services enhances their convenience and enhances the population's confidence in the health system. This has been shown to be the case for community-based HIV care in Haiti, for example (Farmer et al., 2001; Walton et al., 2004). Improving patients' experience of care and patient-provider communication was one of the objectives of the family medicine reforms in the countries of the former Soviet Union. The introduction of family physicians charged with continuous and single-source care for most of a family's health needs has been associated with high levels of patient satisfaction in Poland and Estonia (Kalda, Polluste, Maaroos, \& Lember, 2004; Polluste, Kalda, \& Lember, 2000, 2004, 2007). The primary care expansions in Latin America have in some cases featured a strong element of community participation, although they are still subject to criticism for inadequate consultation of communities and top-down decision making (Arredondo \& Orozco, 2006; Laurell, 2007; Lewis, Eskeland, \& Traa-Valerezo, 2004).

\section{Health system strengthening}

Several of the primary care initiatives we reviewed have been framed as a means of strengthening the broader health system. This 
is certainly the case for the Latin American reforms that are described as an opportunity to both expand and rationalize health service delivery to rural areas, and thus expand the reach of the health system. These initiatives necessitated capacity building in the areas of planning, budgeting, and management at both central and district levels, that may benefit the stewardship of the health system overall (Frenk, Gonzalez-Pier, Gomez-Dantes, Lezana, \& Knaul, 2006; Gakidou et al., 2006). Initiatives such as IMCI have improved overall quality of care for sick children presenting in primary care facilities (Bryce et al., 2005). The impact of rural and decentralized HIV care on health systems has been debated, but experience in Haiti suggests that a broad-based approach involving the upgrading of health centers to provide counseling, testing, and antiretrovirals can result in collateral benefits for other health services (Farmer et al., 2001; Walton et al., 2004). The implementation of primary care packages in post-conflict countries is also tightly integrated with health system development. For example, motivated by the large-scale expansion of the Basic Package of Health services (BPHS), health information systems in Afghanistan are being built that can report on service utilization for a range of services (Peters et al., 2007).

\section{Equity}

\section{Equitable access and outcomes}

Equity in both service utilization and in health outcomes is a central concern in the majority of the initiatives reviewed here. This is reflected in the relatively large number of evaluations that report equity outcomes (Table 2). For example, both Costa Rica and Brazil selected economically disadvantaged areas of their countries for the implementation of their primary care initiatives and as a result reduced the gap in access to services between rich and poor (RoseroBixby, 2004). In Mexico, the poor have enrolled disproportionately in Seguro Popular (Gakidou et al., 2006). Focusing on rural areas is a common strategy to reduce inequities, as demonstrated by primary care reforms in Iran, Latin America, and Sri Lanka, among others. Thailand also explicitly focused its primary care efforts on rural areas, for example, increasing the supply of generalist physicians to rural areas, offering rural health insurance, and expanding rural clinics. As a result, relative mortality among the poorest children fell much faster than among richest children and the poor-rich gap in mortality decreased by more than half between 1990 and 2000 (Vapattanawong et al., 2007). In Afghanistan, while rural coverage with maternal and child health services still lags that of urban areas, it has also improved since the introduction of the BPHS (Johns Hopkins University \& Indian Institute of Health Management Research, 2006).

On the other hand, interventions such as IMCI, although intended to reduce mortality among poor children, have been implemented in wealthier areas first in some countries and so have not improved equity of access or outcomes. equity. This was likely motivated by ease of implementation (better infrastructure, more health workers) and has been identified as an area for re-examination (Victora et al., 2006). Mixed results for equity have also been found for IMCI in Tanzania (Masanja, Schellenberg, de Savigny, Mshinda, \& Victora, 2005). Equity is also under threat in some of the countries and regions with longtime commitment to primary care. In Kerala, underfunding of primary care and shortages of doctors in rural areas are pushing the poor to shift from publicly funded primary care clinics to private health care at much higher cost (Nair, 2004). Similarly, there are concerns about widening gaps in health outcomes in Sri Lanka where health system funding has not kept pace with the rise in chronic disease and an aging population, with the result that growing proportions of rural dwellers are bypassing understaffed, and poorly equipped government clinics to seek health care in private clinics or hospitals (Withanachchi \& Uchida, 2006).

\section{Financial protection}

Although primary health service delivery is not itself a financing intervention, fair financing is an important feature of many primary care programs. Most, although not all, programs offer services that are free at the point of care, financed either via inexpensive public insurance or through direct tax-based financing. Adequate and equitable funding is crucial to protecting families from hardship related to the costs of seeking primary health services. This is demonstrated in former "model" primary care systems such as those of Kerala and Sri Lanka where underfunding of primary care delivery in rural areas is raising out-of-pocket spending for the poor who are forced to use private providers or travel further to get quality health care (Varatharajan, Thankappan, \& Jayapalan, 2004; Withanachchi \& Uchida, 2006). An important mechanism by which primary care can reduce the financial burden on families is to reduce over-treatment, particularly the excessive use of medications and multiple providers. For example, the use of facilities offering IMCI was found to be associated with lower out-of-pocket payments by families, compared to non-IMCI facilities, primarily due to more rational drug use (Manzi et al., 2005). Only the reforms in Mexico explicitly assessed the impact of the initiative on impoverishing health spending, finding that increased access to services was associated with lower levels of such spending in communities affiliated with Seguro Popular (Knaul et al., 2006). While it is likely that comprehensive primary care would reduce out-of-pocket costs for patients by rationalizing treatment and reducing travel and other transaction costs, this requires further study.

\section{Efficiency}

\section{Costs of providing care}

Only a few of the studies here discussed the costs of providing primary care in the developing world. Furthermore, studies that did address costs tended to be from middle-income rather than lowincome countries (Table 2). The low cost of providing universal coverage and good health outcomes has been noted in Cuba, Sri Lanka, and Kerala, India. Administrative data from Latin America can suggest cost range for multi-component initiatives: Brazil's family health program (PSF) was estimated to cost USD 30 per capita in the regions covered. In 2005, total health spending in Brazil was USD 371 per capita, thus this initiative cost less than $10 \%$ of the country's health budget (WHO, 2007). Costs of IMCI were comparable to standard care for sick children, and were associated with improvements in mortality, suggesting it was cost-effective. The use of non-physician primary care clinicians was associated with lower training and deployment costs than the use of physicians in Africa (Dovlo, 2004). In low- and middle-income countries, where overall resource envelopes for health do not permit a specialized care alternative and comparative analyses are not possible, the main question perhaps is whether countries can afford primary care. The Commission on Macroeconomics and Health has calculated that it costs USD 35-USD 40 per capita to provide a wide range of essential health services (WHO, 2001). This figure has been used widely as a floor for health care spending in the developing world. Even this relatively low amount may not be affordable at current rates health spending in low-income countries, although these amounts have been exceeded and appear sustainable in middle-income countries, such as Mexico and Brazil.

\section{Discussion and conclusions}

The best evidence for the effectiveness of primary care in achieving health system goals comes from some of the recent Latin American experiments in expanding rural primary care services to broad segments of the population. However, although evidence 
directly attributing health and other benefits to primary care in other low-income regions is not as strong, from the experiences reviewed here, it appears that primary care initiatives are contributing to increased access to services as well as equity in access and outcomes. Moreover, primary care is emerging as a foundation for health systems strengthening in the developing world-from countries rebuilding after conflict, such as Afghanistan and Liberia, to African countries rethinking the delivery of an ever growing set of health services to large rural populations to meet the health MDGs, to countries in Eastern Europe reforming health care delivery to reign in costs and improve responsiveness. We also found that primary care is a fertile field for innovation in areas ranging from financing, to community involvement, to health worker training.

\section{Limitations}

One of the main limitations to inference about the overall effectiveness of primary care is the relatively low number and poor quality of evaluations available for many of the major primary care initiatives. Of 76 studies reviewed, 48 (63.1\%) employed a preexperimental or observational design, 24 (31.6\%) employed a quasiexperimental design, and only 4 (5.3\%) employed an experimental design. Relatively few programs included control groups and thus made it impossible to rule out alternative (non-intervention related) explanations for results observed. We note that those studies that did employ quasi-experimental and experimental designs tended to come disproportionately from middle-income rather than low-income countries, for example, Mexico and Brazil. This limitation is consistent with recent findings of the Alliance for Health Policy and Systems Research (AHPSR), who concluded that insufficient funding, lack of donor coordination, and a lack of national capacity were key constraints to the development of effective health policy research institutions in low-income countries (Bennett et al., 2008). For example, in 2008, an average lowincome country received 2.2 health policy and systems research grants with a median value of 23,000 USD, compared to 3.6 grants (median value 30,000 USD) in middle-income countries, and 12.4 grants (median value 675,000 USD) in high-income countries.

Another important limitation of this review is the inclusion of multiple components in the primary care programs reviewed, leading to difficulties in attribution of effects specifically to the primary care component. Finally, nearly all studies reviewed found that the primary care intervention under investigation had an impact of one type or another, suggesting publication bias. Given the preponderance of pre-experimental and observational evidence, the multi-component nature of the initiatives, and potential publication bias, we would consider the evidence presented here to be indicative rather than definitive.

Limitations considered, primary care-focused large health initiatives throughout the developing world have shown encouraging results in improving health outcomes and access to care, including among the poor, at reasonably low cost. Primary care has also been explicitly used as a platform for health system strengthening in several countries. Primary care also faces some important challenges, including the epidemiologic transition to chronic disease, health system decentralization, erosion of health funding, and competition with vertical programs. Sri Lanka, Kerala, India, and Cuba, long models of well-functioning primary care systems, are increasingly straining to maintain their health outcomes and equitable service provision.

In concluding we outline a potential research agenda for primary care. While there is a large body of research suggesting improved access, health, and lower costs for primary care versus specialistbased care in high-income countries, several questions remain about the role of primary care in low- and middle-income countries. Perhaps the most important of these is how best to deliver integrated primary care to maximize impact on health outcomes and equity given major funding constraints. This research question can be best addressed by implementation or delivery science research, a new domain of work that is concerned with closing the "know-do" gap with rigorous study of the best means of delivering potentially powerful health interventions in real-world settings (Madon, Hofman, Kupfer, \& Glass, 2007).

Specific areas of implementation research for primary care in lowincome countries include: strategies to achieve and maintain quality of care that are feasible in resource-constrained settings, sustainable financing strategies for primary care, new measurement approaches for continuity of care, responsiveness, and financial impacts, sustainable models of integration of primary care with secondary services, and approaches for national scale-up of successful initiatives. It will also be important to clarify which components of extant primary care models are generalizable to different settings.

One feasible approach for conducting implementation research is through rigorous evaluations of national primary care initiatives. Such evaluations should be planned in tandem with the roll out of new primary care programs to permit prospective study and carefully chosen, ideally random, comparison groups (Berman, 2000; Macinko et al., 2009). Implementation research in primary care should become an integral component of health system research agendas in low-income countries and needs to be supported by development partners. The recent increase in development assistance for health (Ravishankar et al., 2009) may provide opportunities to replicate in Africa and other low-income regions the large-scale, well-designed evaluations that have done a great deal to clarify the contribution of primary care to achieving health system goals in Latin America and Asia.

\section{Appendix. Supplementary material}

Supplementary data associated with this article can be found in the online version, at doi:10.1016/j.socscimed.2009.11.025.

\section{References}

Arredondo, A., \& Orozco, E. (2006). Effects of health decentralization, financing and governance in Mexico. Rev Saude Publica, 40(1), 152-160.

Atun, R. (2004). What are the advantages and disadvantages of restructuring a health care system to be more focused on primary care services? London: Health Evidence Network.

Baicker, K., \& Chandra, A. (2004). Medicare spending, the physician workforce, and beneficiaries' quality of care. Health Affairs (Millwood)(Suppl. Web Exclusives), W184-W197.

Bennett, S., Adam, T., Zarowsky, C., Tangcharoensathien, V., Ranson, K., Evans, T., et al. (2008). From Mexico to Mali: progress in health policy and systems research. Lancet, 372(9649), 1571-1578.

Berman, P. (2000). Organization of ambulatory care provision: a critical determinant of health system performance in developing countries. Bulletin of the World Health Organisation, 78(6), 791-802.

Briggs, C. J., Capdegelle, P., \& Garner, P. (2001). Strategies for integrating primary health services in middle- and low-income countries: effects on performance costs and patient outcomes. Cochrane Database of Systematic Reviews(4). CD003318.

Brockerhoff, M., \& Derose, L. F. (1996). Child survival in East Africa: the impact of preventive health care. World Development, 24(12), 1841-1857.

Bryce, J., Gouws, E., Adam, T., Black, R. E., Schellenberg, J. A., Manzi, F., et al. (2005). Improving quality and efficiency of facility-based child health care through integrated management of childhood illness in Tanzania. Health Policy Plan 20(Suppl. 1), i69-i76.

Chan, M. (2007). The contribution of primary health care to the millennium development goals. In International conference on health for development. Buenos Aires, Argentina: WHO.

Chan, M. (2008). Return to Alma-Ata. The Lancet, 372(9642), 865-866.

Chen, L., Evans, T., Anand, S., Boufford, J. I., Brown, H., Chowdhury, M., et al. (2004). Human resources for health: overcoming the crisis. Lancet, 364(9449), 1984-1990.

Declaration of Alma-Ata. (1978). In International conference on primary health care, Alma-Ata, USSR

Dovlo, D. (2004). Using mid-level cadres as substitutes for internationally mobile health professionals in Africa. A desk review. Human Resource for Health, 2(1), 7. 
Dugbatey, K. (1999). National health policies: sub-Saharan African case studies (1980-1990). Social Science \& Medicine, 49(2), 223-239.

Engstrom, S., Foldevi, M., \& Borgquist, L. (2001). Is general practice effective? A systematic literature review. Scandinavian Journal of Primary Health Care 19(2), 131-144.

Farmer, P., Leandre, F., Mukherjee, J. S., Claude, M., Nevil, P., Smith-Fawzi, M. C., et al. (2001). Community-based approaches to HIV treatment in resource-poor settings. Lancet, 358(9279), 404-409.

Franks, P., \& Fiscella, K. (1998). Primary care physicians and specialists as personal physicians. Health care expenditures and mortality experience. Journal of Family Practice, 47(2), 105-109.

Frenk, J., Gonzalez-Pier, E., Gomez-Dantes, O., Lezana, M. A., \& Knaul, F. M. (2006). Comprehensive reform to improve health system performance in Mexico. Lancet, 368, 1524-1534.

Gakidou, E., Lozano, R., Gonzalez-Pier, E., Abbott-Klafter, J., Barofsky, J. T., BrysonCahn, C., et al. (2006). Assessing the effect of the 2001-2006 Mexican health reform: an interim report card. Lancet, 368(9550), 1920-1935.

Health Council of the Netherlands. (2004). European primary care. The Hague.

Hill, A. G., MacLeod, W. B., Joof, D., Gomez, P., \& Walraven, G. (2000). Decline of mortality in children in rural Gambia: the influence of village-level primary health care. Tropical Medicine and International Health, 5(2), 107-118.

Johns Hopkins University, \& Indian Institute of Health Management Research. (2006). 2006 Afghanistan Household Survey.

Kalda, R., Polluste, K., Maaroos, H. I., \& Lember, M. (2004). Patients' opinions on family doctor accessibility in Estonia. Croatian Medical Journal, 45(5), 578-581.

Kekki, P. (2006). Primary health care and the millennium development goals: Issues for discussion. Helsinki: University of Helsinki.

Knaul, F. M., Arreola-Ornelas, H., MÈndez-Carniado, O., Bryson-Cahn, C., Barofsky, J., Maguire, R., et al. (2006). Evidence is good for your health system: policy reform to remedy catastrophic and impoverishing health spending in Mexico. The Lancet, 368(9549), 1828-1841.

Kruk, M. E., \& Freedman, L. P. (2008). Assessing health system performance in developing countries: a review of the literature. Health Policy, 85, 263-276.

Laurell, A. C. (2007). Health system reform in Mexico: a critical review. International Journal of Health Services, 37(3), 515-535.

Lewis, M., Eskeland, G., \& Traa-Valerezo, X. (2004). Primary health care in practice: is it effective? Health Policy, 70(3), 303-325.

Macinko, J., Guanais, F. C., de Fatima, M., \& de Souza, M. (2006). Evaluation of the impact of the family health program on infant mortality in Brazil, 1990-2002. Journal of Epidemiology and Community Health, 60(1), 13.

Macinko, J., Starfield, B., \& Erinosho, T. (2009). The impact of primary healthcare on population health in low - and middle-income countries. Journal of Ambulatory Care Management, 32(2), 150-171.

Macinko, J., Starfield, B., \& Shi, L. (2003). The contribution of primary care systems to health outcomes within Organization for Economic Cooperation and Development (OECD) countries, 1970-1998. Health Services Research, 38(3), 831-865.

Madon, T., Hofman, K. J., Kupfer, L., \& Glass, R. I. (2007). Public health: implementation science. Science, 318(5857), 1728-1729.

Magnani, R. J., Rice, J. C., Mock, N. B., Abdoh, A. A., Mercer, D. M., \& Tankari, K. (1996) The impact of primary health care services on under-five mortality in rura Niger. International Journal of Epidemiology, 25(3), 568-577.

Manzi, F., Schellenberg, J. A., Adam, T., Mshinda, H., Victora, C. G., \& Bryce, J. (2005). Out-of-pocket payments for under-five health care in rural southern Tanzania. Health Policy E' Planning, 20(Suppl. 1), i85-i93.

Masanja, H., Schellenberg, J. A., de Savigny, D., Mshinda, H., \& Victora, C. G. (2005). Impact of integrated management of childhood illness on inequalities in child health in rural Tanzania. Health Policy Plan, 20(Suppl. 1), i77-i84.

Ministry of Health of Brazil Department of Primary Care. (2007). Atencao basica a saude da familia [Primary care and family health].

Ministry of Public Health of Afghanistan. (2008). Kabul: Ministry of Public Health News.

Montegut, A. J. (2007). To achieve "health for all" we must shift the world's paradigm to "primary care access for all". Journal of American Board of Family Medicine, 20(6), 514-517.

Mullan, F., \& Frehywot, S. (2007). Non-physician clinicians in 47 sub-Saharan African countries. Lancet, 13, 13.

Nair, V. M. (2004). Health in South Asia: future of Kerala depends on its willingness to learn from past. British Medical Journal, 328(7454), 1497.

Nasseri, K., Sadrizadeh, B., Malek-Afzali, H., Mohammad, K., Chamsa, M., Cheraghchi-Bashi, M. T., et al. (1991). Primary health care and immunisation in Iran. Public Health, 105(3), 229-238.

van Palenstein Helderman, W., Mikx, F., Begum, A., Adyatmaka, A., Bajracharya, M., Kikwilu, E., et al. (1999). Integrating oral health into primary health careexperiences in Bangladesh, Indonesia, Nepal and Tanzania. International Dental Journal, 49(4), 240-248.
Pence, B. W., Nyarko, P., Phillips, J. F., \& Debpuur, C. (2007). The effect of community nurses and health volunteers on child mortality: the Navrongo Community Health and Family Planning Project. Scandinavian Journal of Public Health, 35(6), 599-608.

Perry, H. B., Shanklin, D. S., \& Schroeder, D. G. (2003). Impact of a community-based comprehensive primary healthcare programme on infant and child mortality in Bolivia. Journal of Health Population and Nutrition, 21(4), 383-395.

Perry, H., Robison, N., Chavez, D., Taja, O., Hilari, C., Shanklin, D., et al. (1998). The census-based, impact-oriented approach: its effectiveness in promoting child health in Bolivia. Health Policy Plan, 13(2), 140-151.

Peters, D. H., Noor, A. A., Singh, L. P., Kakar, F. K., Hansen, P. M., \& Burnham, G. (2007). A balanced scorecard for health services in Afghanistan. Bulletin World Health Organisation, 85(2), 146-151.

Polluste, K., Kalda, R., \& Lember, M. (2000). Primary health care system in transition: the patient's experience. International Journal of Quality of Health Care, 12(6), 503-509.

Polluste, K., Kalda, R., \& Lember, M. (2004). Evaluation of primary health care reform in Estonia from patients' perspective: acceptability and satisfaction. Croatian Medical Journal, 45(5), 582-587.

Polluste, K., Kalda, R., \& Lember, M. (2007). Satisfaction with the access to the health services of the people with chronic conditions in Estonia. Health Policy, 82(1), 51-61.

Ravishankar, N., Gubbins, P., Cooley, R. J., Leach-Kemon, K., Michaud, C. M., Jamison, D. T., et al. (2009). Financing of global health: tracking development assistance for health from 1990 to 2007. Lancet, 373(9681), 2113-2124.

Rohde, J., Cousens, S., Chopra, M., Tangcharoensathien, V., Black, R., Bhutta, Z. A., et al. (2008). 30 years after Alma-Ata: has primary health care worked in countries? Lancet, 372(9642), 950-961.

Rosero-Bixby, L. (2004). Spatial access to health care in Costa Rica and its equity: a GIS-based study. Social Science \& Medicine, 58(7), 1271-1284.

Schieber, G. J., Gottret, P., Fleisher, L. K., \& Leive, A. A. (2007). Financing global health: mission unaccomplished. Health Affairs, 26(4), 921-934.

Starfield, B. (1992). Primary care: Concept, evaluation, and policy. New York: Oxford University Press.

Starfield, B., Shi, L., \& Macinko, J. (2005). Contribution of primary care to health systems and health. Milbank Q 83(3), 457-502.

Tanzania IMCI Multi-country Evaluation Health Facility Survey Study Group. (2004). The effect of integrated management of childhood illness on observed quality of are of under-fives in rural Tanzania. Health Policy and Planning, 19(1), 1-10.

Unger, J.-P., De Paepe, P., Buitron, R., \& Soors, W. (2008). Costa Rica: achievements of a heterodox health policy. American Journal of Public Health, 98(4), 636-643.

Vapattanawong, P., Hogan, M. C., Hanvoravongchai, P., Gakidou, E., Vos, T., Lopez, A. D., et al. (2007). Reductions in child mortality levels and inequalities in Thailand: analysis of two censuses. The Lancet, 369(9564), 850-855.

Varatharajan, D., Thankappan, R., \& Jayapalan, S. (2004). Assessing the performance of primary health centres under decentralized government in Kerala, India. Health Policy and Planning, 19(1), 41-51.

Velema, J. P., Alihonou, E. M., Gandaho, T., \& Hounye, F. H. (1991). Childhood mortality among users and non-users of primary health care in a rural west African community. International Journal of Epidemiology, 20(2), 474-479.

Victora, C. G., Huicho, L., Amaral, J. J., Armstrong-Schellenberg, J., Manzi, F., Mason, E., et al. (2006). Are health interventions implemented where they are most needed? District uptake of the integrated management of childhood illness strategy in Brazil, Peru and the United Republic of Tanzania. Bulletin World Health Organisation, 84(10), 792-801.

Villalbi, J. R., Guarga, A., Pasarin, M. I., Gil, M., Borrell, C., Ferran, M., et al. (1999). An evaluation of the impact of primary care reform on health. Aten Primaria, 24(8), 468-474.

Walton, D. A., Farmer, P. E., Lambert, W., Leandre, F., Koenig, S. P., \& Mukherjee, J. S. (2004). Integrated HIV prevention and care strengthens primary health care: lessons from rural Haiti. Journal of Public Health Policy, 25(2), 137-158.

Welch, W. P., Miller, M. E., Welch, H. G., Fisher, E. S., \& Wennberg, J. E. (1993). Geographic variation in expenditures for physicians' services in the United States. New England Journal of Medicine, 328(9), 621-627.

WHO. (2000). World health report: health systems improving performance. Geneva, Switzerland.

WHO. (2001). Macroeconomics and health: Investing in health for economic development; Report of the commission on macroeconomics and health. Geneva: World Health Organization.

WHO. (2007). World Health Organization statistical information system: Core health indicators.

WHO. (2008a). Integrating mental health into primary care: A global perspective. Geneva: WHO.

WHO. (2008b). World Health Report 2008: Primary health care - Now more than ever. Geneva: WHO

Withanachchi, N., \& Uchida, Y. (2006). Healthcare rationing: a guide to policy directions in Sri Lanka. Health Policy, 78(1), 17-25. 